\title{
Progressive Bulbar Palsy
}

National Cancer Institute

\section{Source}

National Cancer Institute. Progressive Bulbar Palsy. NCI Thesaurus. Code C85026.

A progressive motor neuron disorder affecting the muscles which are innervated by cranial nerves of the lower brain stem. Signs and symptoms include difficulties in chewing and swallowing, dysarthria, and weakness of the facial muscles and tongue. 